Slavica

bruxellensia

\section{Slavica bruxellensia}

Revue polyphonique de littérature, culture et histoire

slaves

$2 \mid 2009$

Femme(s)

\title{
Ewa Toniak, Olbrzymki. Kobiety i socrealizm
}

\section{Wojciech Tomasik}

Traducteur : Dorota Walczak

\section{CpenEdition}

\section{Journals}

Édition électronique

URL : http://journals.openedition.org/slavica/175

DOI : $10.4000 /$ slavica. 175

ISSN : 2034-6395

Éditeur

Université libre de Bruxelles - ULB

Édition imprimée

Pagination : 74-75

ISSN : 2031-7654

Référence électronique

Wojciech Tomasik, « Ewa Toniak, Olbrzymki. Kobiety i socrealizm », Slavica bruxellensia [En ligne], 2 I

2009, mis en ligne le 15 février 2009, consulté le 22 septembre 2020. URL : http://

journals.openedition.org/slavica/175 ; DOI : https://doi.org/10.4000/slavica.175

Ce document a été généré automatiquement le 22 septembre 2020.

\section{c) (i) $\odot$}

Les contenus de Slavica bruxellensia sont mis à disposition selon les termes de la Licence Creative Commons Attribution - Pas d'Utilisation Commerciale - Pas de Modification 3.0 France. 


\section{Ewa Toniak, Olbrzymki. Kobiety $i$ socrealizm}

\section{Wojciech Tomasik}

Traduction : Dorota Walczak

\section{RÉFÉRENCE}

Ewa Toniak, Olbrzymki. Kobiety i socrealizm, Cracovie, Korporacja Ha! art, Série « Linia wizualna ", $\mathrm{n}^{\circ} 1,2008,166 \mathrm{p}$.

\section{NOTE DE L'ÉDITEUR}

La langue originelle de cette recension est le polonais 
1

Dans Olbrzymki. Kobiety $i$ socrealizm (Les Géantes. Les femmes et le réalisme socialiste), Ewa Toniak se base sur le constat que l'art polonais de la période réaliste socialiste propose une sorte de discours classique et patriarcal. L'attention de l'auteur est focalisée sur l'image de la femme, telle qu'elle apparaît dans des réalisations artistiques (peintures, sculptures, films documentaires et de fiction, œuvres littéraires et couvertures de magazines des années 1950) et à travers le récit des « bâtisseurs d'un avenir meilleur ", récit dans lequel il y a, comme elle le remarque, un manque profond de cohérence. Le réalisme socialiste se définit comme un art qui proclame l'égalité des sexes, mais, dans son application et sa réalisation

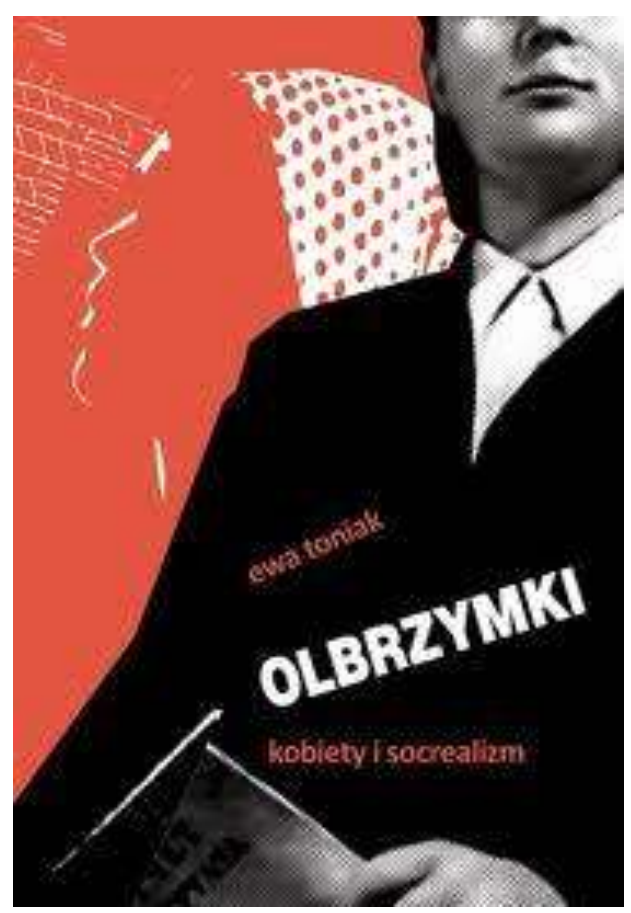
textuelles, on remarque que les valeurs traditionnellement associées au rôle social masculin sont mises en exergue.

2 La chercheuse aborde le réalisme socialiste polonais sous l'angle de l'opposition homme-femme et montre que, derrière une façade d'égalité, se cachent la violence, l'agression, la réification. Car, sous le communisme, la «question féminine » est posée et débattue par les hommes.

3 Toniak montre l'opposition des sexes dans la relation mot-image et décrit ainsi une culture qui se caractérise par un déséquilibre: la domination du masculin et de l'expression verbale. Bien que révolutionnaire dans ses postulats, la culture communiste raffermit l'ordre traditionnel, dans lequel la parole se situe du côté des hommes actifs (et qui regardent), tandis que le silence reste du côté des femmes passives (et regardées).

4 L'auteur introduit dans son livre un cheminement intellectuel très intéressant. Nous pourrions le qualifier de récit sur la façon dont l'impérieux discours masculin est démasqué, désarmé, compromis et parodié par les femmes dans l'art polonais. L'auteur parle du réalisme socialiste non seulement comme un phénomène historiquement fermé, mais aussi comme le point de départ de tout ce qui se passe dans l'art polonais contemporain, c'est-à-dire après les années de dictature masculine et communiste.

Dans ce dialogue, elle s'engage personnellement. Contrairement à son sujet, le livre est féminin, et ce de manière ostentatoire. Nous pouvons lire dans la première phrase que ces esquisses "sont nées de l'ennui ». Olbrzymki rappelle dans sa structure un patchwork délicat opposé aux œuvres de l'époque, solides, monumentales et construites selon les directives imposées. Le réalisme socialiste accordait la primauté au mot et, dans ce système, la littérature tenait le rôle central : le pouvoir utilisait la matière textuelle pour asseoir sa force. Le sens de l'image est soumis à un contrôle : par exemple, via un commentaire ajouté aux scènes d'un film, un titre très expressif, une légende sous une photographie, etc. 
6 L'ouvrage renverse cette hiérarchie : le mot, que la culture communiste plaçait au centre, est ici mis en marge de la réflexion. Le matériel à la base de l'analyse est surtout composé de toiles, de sculptures, de cadres, de films, de photos de couvertures et de photomontages. De plus, le livre est richement illustré. En mettant au premier plan l'image féminine, " anarchique » dans sa sémantique, et au second le mot masculin qui contrôle le sens de l'image, l'art polonais des années 1950 dévoile ainsi ce qu'il ne voulait et ne pouvait pas montrer : sa misogynie.

7 Olbrzymki est le premier livre d'Ewa Toniak et le premier volume de la nouvelle série « Linia wizualna ». Ces débuts sont très prometteurs.

INDEX

Index géographique : Pologne

Mots-clés : féminisme, réalisme socialiste

Index chronologique : communisme, XXe siècle

\section{AUTEURS}

WOJCIECH TOMASIK

Professeur à l'Université de Bydgoszcz (Pologne) 